\title{
Techniques for determining importance: Balancing scientific method and subjectivity
}

Received (in revised form): 17th January, 2007

\section{Gwen Fontenot}

is an assistant professor of marketing in the Moody College of Business at the University of Louisiana at Lafayette. She has 25 years of experience conducting marketing research and remains active in her own full-service marketing research firm.

\section{Lucy Henke}

is an associate professor in the Department of Marketing and Legal Studies at the University of Louisiana at Lafayette. She has worked for ABC Television Network News Research and Louis Harris and Associates in New York, and has authored or coauthored over 20 articles in refereed academic journals.

\section{Kerry Carson}

is a professor of management in the Moody College of Business at the University of Louisiana at Lafayette. His research and consulting interests include employee surveying and performance management.

\section{Paula Phillips Carson}

is a professor of management in the Moody College of Business at the University of Louisiana at Lafayette. She has published over 60 referred articles and six books on human resource and service issues.

Keywords derived importance, stated importance, importance measurement, customer satisfaction

Abstract As researchers seek to find optimal techniques to help make customer satisfaction data more actionable, the question of how to obtain data on the importance of attributes impacting customer satisfaction continues to surface. This study examines the issue of identifying importance by using one method of stated importance and three methods of derived importance in an attempt to determine whether one method should be favoured over another. When methods yield apparently inconsistent results, the role of the researcher in interpreting data and in establishing the meaning and implications of the results of statistical analysis is, however, critical.

Journal of Targeting, Measurement and Analysis for Marketing (2007) 15, 170-180. doi:10.1057/palgrave.jt.5750043

\section{INTRODUCTION}

Researchers continually strive to find the best methods to use in analysing customer satisfaction data. In this case, 'best' has a broad definition including the techniques that will provide the most actionable data, will use the most cost-

\footnotetext{
Correspondence: Gwen Fontenot, Assistant Professor of Marketing, Department of Marketing and Legal Studies, University of Louisiana Lafayette, LA 70504, Lafayette, USA.

Tel: +1337482 6316;

Fax: +1337482 5898;

E-mail: fontenotg@louisiana.edu
}

efficient methods and, unfortunately, sometimes even allow the easiest techniques to be used. Significant research has been published communicating various techniques that will help researchers identify the best course of action when evaluating customer satisfaction data. ${ }^{1,2}$ Many of those techniques emphasise the use of an importance measure along with a measure of performance. This importance measure alone raises a significant question - 'What is the best means of determining the customers' perceptions of how important each attribute is?'. 
The issue of derived versus stated importance is one that has been debated for many years. While there is a considerable deliberation over this issue, most researchers agree that no one method is adequate. If forced to choose between derived and stated importance, some prefer stated importance, in part due to the ease with which it is administered and interpreted. Many, however, suggest that derived importance would be their choice primarily due to the confidence afforded to them by the resulting statistical model. ${ }^{3-7}$

The purpose of the paper is to compare one measure of self-stated importance and three analytical methods of derived importance, and to identify the role of researcher expertise in resolving discrepancies in results. Rather than using a 'snapshot' of data, the present study examines ratings of the same companies over a two-year period, to allow greater comparison of the various methods of measurement used. The value of the decision maker's experiential knowledge in reconciling and integrating conflicting results will be discussed.

Customer satisfaction surveys are conducted by many organisations, but the utility of this data has been questioned. Even sophisticated approaches may have serious flaws because they tend to be complicated, ambiguous, have poor response rates, and are not associated with company profit and growth. ${ }^{8}$ While some identify problems with collecting customer satisfaction, others come to its defence. They suggest that customer satisfaction is an important concept that is significantly related to an organisation's profitability. ${ }^{9}$ Others suggest that results have been confusing because customer satisfaction is more valid in some industries, such as retail and entertainment, as compared to others, such as transportation and manufacturing. ${ }^{10}$ Additionally, rather than presuming a current effect, customer satisfaction influence on organisational outcomes may be lagged. ${ }^{11}$

Whether it is argued that customer satisfaction surveys are relevant or not, marketing researchers recognise that surveying is currently being conducted, and this trend will continue, for many reasons. The method is reasonably inexpensive, is easy to understand, gives comparable time series data and appears to close a communication gap with the customer. Typically, managers do not look to optimise their decision-making process. Rather, they tend to look for logical answers near the issue. Conducting customer surveys satisfies managers' needs and provides them with a sense of control. ${ }^{12}$

\section{STATED IMPORTANCE}

When using stated importance, respondents are asked to explicitly state their perception of the importance of each attribute being measured in a customer satisfaction survey. Stated importance can be obtained fairly easily by using a rating scale, rank order or a constant sum. ${ }^{13}$

Researchers commonly use 5-7- or 10-point scales to obtain importance ratings. The lower end of the rating scale (1) is typically noted as 'not important at all' with the high end of the scale being identified as 'extremely important' or 'very important'.

When using rank order to obtain stated importance, respondents are asked to place the attributes in order from most important (1) to least important (maximum rank is the number of total attributes examined).

The constant sum requires the respondents to divide 100 points among all attributes with the most important attributes receiving the greatest number of points. Attributes that are not important are assigned a value of 0 . Any number between 0 and 100 can be used. The same number can be used more than once as long as the sum of all values assigned is 100 .

These straightforward methods allow for easy collection of data and calculation of an importance value for each attribute. They provide an assessment based on the customers' priorities. Such measures, particularly when used to calculate a customer satisfaction index (CSI), can be useful when companies are attempting to identify the strengths and weaknesses of their company as compared to their competitors, as perceived by the customers. ${ }^{14,15}$ Additionally, some researchers feel that these self-stated measures of importance provide face validity that can only be obtained in this manner. ${ }^{16,17}$

While providing a simple means of assessing importance, the stated importance techniques are 
fraught with issues for debate among researchers. Some of these issues include cost efficiencies relative to survey administration and analysis, variability of importance among attributes relative contribution to overall satisfaction, and impact of the attributes on satisfaction.

In order to obtain self-stated importance ratings, the customer satisfaction survey must contain twice the number of questions, one each for importance and satisfaction for each attribute included. Respondents often view this as a repetitive and tedious task. ${ }^{18,19}$ A strong correlation between performance or satisfaction ratings and importance ratings often results as respondents sometimes lose sight of exactly what they are rating. ${ }^{20}$ If using the rank order or constant sum methods, the length of the survey will not be impacted as significantly. Yet, even those methods will require more of the respondents' time than simply asking about performance. On telephone surveys, every minute will impact the cost of the study. Additionally, longer surveys are likely to negatively impact response rates. All of these factors ultimately affect the cost and quality of the survey.

Although some would argue that higher point rating scales (7- or 10-point scales) and the constant sum method allow respondents to sufficiently differentiate between attributes' importance levels, studies show that there is little statistical variation in responses when using stated rather than derived importance methods. ${ }^{21,22}$ Consequently, results may limit the researcher's ability to prioritise attributes in terms of importance to respondents.

A further limitation of the stated importance techniques, identifying relative contribution of attributes, is a strength of some of the derived importance techniques. Simply put, the relationship among attributes and the relationship between attributes and overall satisfaction is unknown when using stated importance. While respondents may consider such relationships when providing their self-stated importance values, those relationships are not visible or known to the researcher and, therefore, cannot be used in analyses. $^{23,24}$ Similarly, the degree to which each attribute contributes to overall satisfaction or the impact the attribute will have in increasing or decreasing satisfaction is unknown when using stated importance. ${ }^{25}$

\section{DERIVED IMPORTANCE}

Deriving a measure of attribute importance in customer satisfaction studies can be accomplished through the use of various techniques. While multivariate analytical techniques such as conjoint analysis have been used by researchers, ${ }^{26}$ correlation and regression analyses are the most commonly used tools in deriving importance. When using either of these tools, each attribute or predictor variable is related to a broader measure or criterion variable, such as overall satisfaction, to identify the attribute's impact on the broader measure.

Three such measures that are closely related include bivariate (Pearson) correlation, standard regression coefficient (or beta weight), and the product of the beta weight and the corresponding Pearson correlation. In rare cases where all attributes are uncorrelated, the three measures will yield identical measures of relative importance ${ }^{27}$ but the use of derived rather than stated importance is not void of its own issues. Problems can result due to multicollinearity (which can be overcome with analytical techniques such as principal component regression, factor analysis, or partial least square regression), missing data and the choice of specific models used in analysis.

The primary drawback of using correlation analysis to derive importance is that, while it provides a measure of the impact of the individual attributes on overall satisfaction, it does not take into account the relationship between variables. In customer satisfaction studies, it is highly unlikely that the attributes do not have any relationship with one another. ${ }^{28-31}$

Research suggests that customers view products and services as a bundle of attributes rather than independent attributes. While the regression model helps researchers understand how the attributes get 'put together' in the respondents' minds, ${ }^{32,33}$ this all-encompassing view by respondents typically means that the attributes are related to one another. For example, when examining satisfaction with automobiles, a study 
might include attributes such as fuel efficiency and cost to operate the vehicle. While the researcher may consider cost to operate as having to do with issues such as fluid or tyre replacement, the respondent may see the amount of fuel needed to operate the car as a cost of operation. In this case, the two variables would be highly correlated and would ultimately impact the results of regression analysis. ${ }^{34-37}$

Additionally, respondents do not always provide a response to every question on a survey. Researchers must determine what to do about responses that are missing. The mean of all responses is often substituted for missing data to allow the respondent's other answers to be included in the analysis, but this can provide misleading results. ${ }^{38}$

Furthermore, the type of regression model used and the level of explanation resulting from the model could hinder the use of this technique used in deriving importance. Researchers recommend using a standard regression model (rather than stepwise, forward or backward selection techniques) for inputting attributes into the model. Use of the various selection techniques can produce differing results. ${ }^{39,40}$ Additionally, a low $R^{2}$ indicates that a high per cent of variance remains unexplained by the model making it difficult to justify to a manager or client that their decision to spend dollars to improve satisfaction should be based on such a model. $^{41}$

Caution must also be used in interpreting the results of regression analysis when an attribute has a regression coefficient that is nonsignificant. Often an attribute will be found to have a negative relationship with overall satisfaction giving the appearance that the presence of the attribute results in a decrease in satisfaction when, in fact, the absence of the attribute would result in a greater decrease in satisfaction. The topic of safety is often discussed as an example of this issue. Looking back at the example of satisfaction with automobiles, a regression analysis might show that safety is not a driver of satisfaction or does not have a significant impact on overall satisfaction. Such findings would imply that a company like Volvo would improve satisfaction if they changed their positioning strategy away from one of providing a high level of safety for their customers. When asked why they purchased a Volvo, many customers, however, indicate that the company's safety record was a major factor in their decision. This suggests that some attributes are considered minimum requirements and do not contribute to customer satisfaction as long as they exist to the necessary degree. ${ }^{42,43}$ Thus, the most basic issue to the consumer may be the reputation of the car for safety. But if all automobiles are relatively similar on this, the most influential factor in determining purchase behaviour may be cost. This type of influencer is often captured by using correlations and regression analyses.

\section{COMPARING TECHNIQUES}

Reasons for using derived importance are in diametric opposition to the reasons for not using stated importance. Derived importance can reduce the cost of obtaining the data yet will likely increase analysis costs as multivariate statistics, rather than descriptive statistics, will need to be used. In contrast, the shorter questionnaire will reduce demands on respondents and likely increase response rates, consequently decreasing overall survey costs. ${ }^{44}$ Further, there may be some response bias inherent in self-stated importance as respondents tend to put more weight on rational, logical issues and less weight on emotional ones. Also, there are differences in prediction and contribution to take into account when deciding on whether to use derived or stated importance.

In a study of travellers' satisfaction with hotels in Hong Kong, $\mathrm{Chu}^{45}$ examined the differences between using stated and derived importance in the calculation of the CSI. Chu used beta coefficients from regression analysis to calculate derived importance and obtain stated importance via respondents' ratings of importance. The results show that a higher CSI is obtained when using stated importance than when using derived importance. Although the attributes that contributed most to customer satisfaction were the same regardless of which importance method was used, Chu perceives that the derived importance method is superior due to its power of prediction and explanation. 
One of the primary advantages to using regression analysis to derive importance is that the regression model provides a statistical model of the relative impact of each attribute on overall satisfaction and also assesses the relationships between attributes. Correlation analysis provides a similar view but only examines the relationship of one attribute at a time with overall satisfaction. Both of these analysis techniques allow the researcher to identify those discriminating or differentiating attributes that will seemingly make the greatest contribution to customer satisfaction. ${ }^{46-49}$

Hanson $^{50}$ and Di Paula ${ }^{51}$ both favour the use of correlation over regression in deriving importance. Hanson's suggestion is based on theoretical and practical experiences with realworld data sets. Di Paula's recommendation is based on a rank order of both derived and stated importance of survey attributes. The rankings were then correlated to examine any differences. Although both sets of rankings were statistically correlated, indicating that both measures captured the same information, he suggested using both techniques initially until it can be determined that the two methods yield the same results. Then, he surmises, it would be safe to eliminate the stated importance measure from future administrations of the survey.

In an examination of three data sets, Gustafsson and Johnson ${ }^{52}$ compared a variety of methods for statistically deriving attribute importance. Similar to the debate on whether to use stated or derived importance, the researchers found that each method of deriving importance has its strengths and weaknesses making it difficult to recommend any one technique over others.

In a document prepared by research associates at the Customer Satisfaction Research Institute, ${ }^{53}$ the authors assert that subjective rather than scientific decisions may need to be applied in assessing importance. The researchers purport that none of the methods alone seems adequate to measure importance. When the scientific method provides results that are ambiguous or even contradictory, then business instinct and intuition may lead to the best decisions.

\section{RESEARCH METHODOLOGY}

\section{Data collection method}

Data for this study were obtained from a customer satisfaction tracking study conducted for a check printer. The same survey was administered to different respondents in each of two years. Responses were received from 256 individuals in the first year and 216 in the second year. The survey included 41 attributes.

Respondents rated the importance of each attribute using a 7-point scale where ' 1 ' was 'not important at all' and ' 7 ' was 'very important'. Respondents also rated their perceptions of the company's performance using a separate 7-point scale where ' 1 ' indicated that they were 'totally dissatisfied' or '7' indicated they were 'totally delighted' with their check printer's performance. Information was collected from both the client's and competitors' customers. To maintain anonymity of results, responses from all respondents, not just customers, were included in this analysis.

The questionnaire was designed in cooperation with management. The attributes included in the study were determined through focus groups held at various locations around the United States.

\section{Data analysis}

Principal component factor analysis with VARIMAX rotation was used to identify the underlying dimensions of the 41 attributes. For purposes of this comparison, standards for including an attribute established by Hair et al. ${ }^{54}$ were followed (attribute loadings greater than or equal to 0.50; eigenvalues greater than or equal to 1.0 and the results of the factor analysis that explain at least 50 per cent of the total variance). Survey design can, however, often impact results. For example, if the list of attributes is not exhaustive, 100 per cent of the phenomenon may not be explained by the model giving the impression that the attributes are not important.

The same analysis was conducted independently on both sets of data resulting in the same five factors each year. The factor analysis suggests that respondents seek (1) quality products, (2) a variety of products, (3) a competitive 
company, (4) ease of doing business and (5) quality service. (Factors were renamed from the actual study to protect the proprietorship of the client's data.)

In addition to computing the average rating of the respondents' stated importance, derived importance was calculated using both correlation and regression analysis. Three derived importance scores are presented: (1) Pearson correlation, (2) beta weights from regression analysis and (3) the product of the beta weights and Pearson correlation.

First, the performance ratings for each factor were correlated with the respondents' ratings of overall satisfaction. Next, the performance ratings for each factor were used as predictors in a regression model where overall satisfaction was the criterion variable. Finally, the correlation coefficients were multiplied by the beta weights derived in the regression analysis to obtain a combined importance score. The importance scores for both the stated and derived importance methods are shown in Tables 1 and 2 .

If the purpose of this study was to identify detailed actions for improving customer satisfaction, further analyses would have been conducted on the specific attributes that comprise each of the factors. Since the purpose is instead to examine the various analysis techniques, analysis of the broader factors is, however, sufficient to illustrate the concepts and provide topic for discussion of the stated and derived importance methods. The following section will examine the results of this research. As with many studies, the reader should, however, use some caution in generalising because of small sample sizes (256 and 216) and the nature of the sample.

\section{RESULTS}

As the literature suggested, the stated importance scores are relatively high on both sets of data and there is little differentiation between the absolute ratings of each factor. Respondents indicated that each of the factors is important to their decision as to which check printer to use. A rating of four is considered average importance on a 7-point scale. Respondents rated one factor, competitive company, slightly above average in importance and rated all other factors important (rating of six or greater). If these stated importance scores were used in identifying actions for improvement or were combined with performance measures to

Table 1: Year One stated and derived importance scores*

\begin{tabular}{lllrr}
\hline & Stated importance & Derived importance & & Pearson*beta weight \\
\cline { 3 - 5 } & & Pearson correlation & $\begin{array}{l}\text { Regression beta } \\
\text { weight }\end{array}$ & 0.110 \\
\hline Quality products & 6.14 & 0.425 & 0.258 & -0.036 \\
Variety of products & 6.19 & 0.309 & 0.08 & 0.027 \\
Competitive company & 4.89 & 0.338 & 0.057 & 0.022 \\
Ease of doing business & 6.15 & 0.381 & 0.222 & 0.094 \\
Quality service & 6.07 & 0.422 & & \\
\hline
\end{tabular}

${ }^{*}$ Factor names have been changed from the original study to protect the proprietary findings.

Table 2: Year Two stated and derived importance scores

\begin{tabular}{lllrr}
\hline & Stated importance & Derived importance & & Pearson*beta weight \\
\cline { 3 - 5 } & & Pearson correlation & $\begin{array}{l}\text { Regression beta } \\
\text { weight }\end{array}$ & 0.293 \\
\hline Quality products & 6.23 & 0.618 & 0.474 & -0.009 \\
Variety of products & 6.12 & 0.539 & -0.017 & 0.043 \\
Competitive company & 4.73 & 0.505 & 0.085 & 0.046 \\
Ease of doing business & 6.39 & 0.544 & 0.084 & 0.017 \\
Quality service & 6.07 & 0.507 & 0.034 & \\
\hline
\end{tabular}

${ }^{\star}$ Factor names have been changed from the original study to protect the proprietary findings. 
calculate a CSI, the lack of variation between them would make it difficult to identify which areas need to be addressed in order to improve customer satisfaction.

When using the correlation coefficients to derive importance, a coefficient of zero $(0)$ indicates that no correlation exists between the factor and overall satisfaction while a coefficient of one (1) indicates a perfect linear relationship between them. The relationship between each factor and overall satisfaction varies in the two years of data examined. In the first year that is examined, the correlation coefficients are below 0.5 indicating none of the factors has a strong relationship with overall satisfaction. This could be interpreted, if causation was to be inferred, to indicate that a change in the company's performance on any of these factors would not significantly impact the customers' satisfaction level with the company. Correlation of the rank order of factors based on stated and derived importance reveals that the two measures do not appear to be capturing the same information.

Figure 1 graphically presents the ranked stated and derived importance scores, where a ' 5 ' rank at the top of the vertical continuum indicates the most important attribute. A cursory review of this chart illustrates the divergence of results between the stated and the derived methodologies as well as the disparity among the three derived techniques. Such inconsistency makes it difficult for analysts to decisively conclude where to focus improvement efforts, unless it can be assumed that the stated and derived approaches are not intended to yield duplicative or substitutable information.

Figure 2 graphically presents the data from Year Two collection. Pattern inconsistency can again be detected, evidencing the conclusion that divergent results are almost predictably generated by the different methodologies.

In an absolute sense, data from the second year shows a stronger, yet not extremely high, relationship between the factors and overall satisfaction. Furthermore, rank orders of factors using both stated and derived importance in the second year resulted in a high level of correlation indicating that both methods are capturing the same information. It should be noted that although the two most important factors were selected by both methods, they were not selected in the same order of importance.

Since both the correlation and regression analyses examine the relationship between the factors and overall satisfaction, it is expected that these methods of deriving importance would result in similar findings. This is the case when using the first year of data. The importance rankings derived from regression generally covary with those derived from the correlation analysis, indicating that little difference in recommendations for important action would result regardless of which technique was employed. The data from the second year, however, yielded more differentiated results when comparing the correlation and regression techniques. In this case, the importance rankings

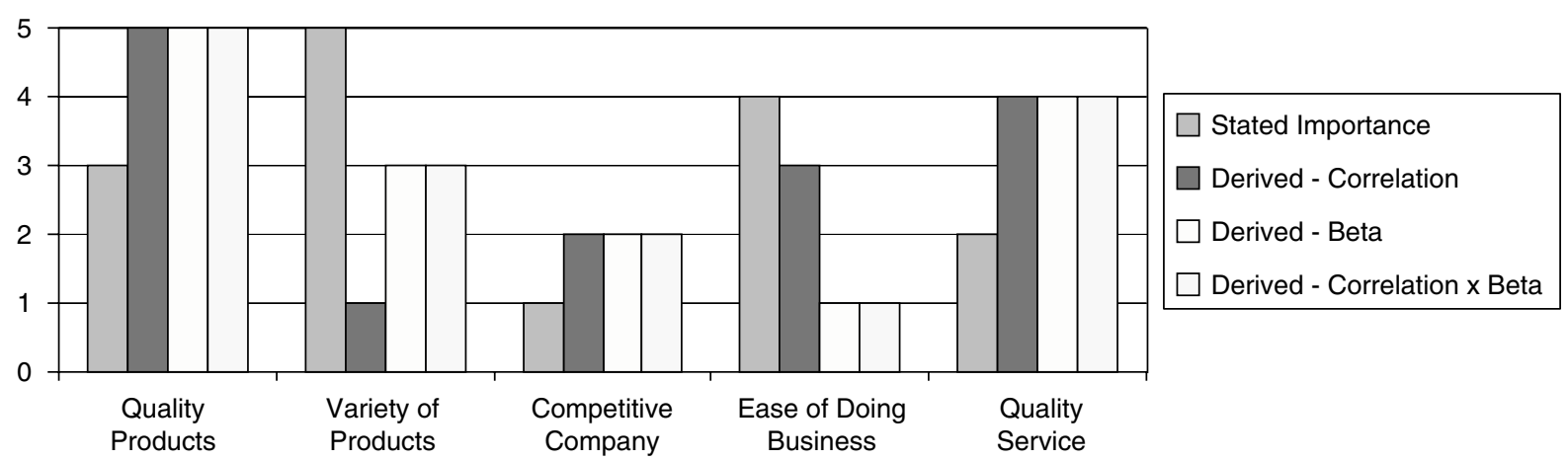

Figure 1: Year One stated and derived importance scores ranked to demonstrate divergence 


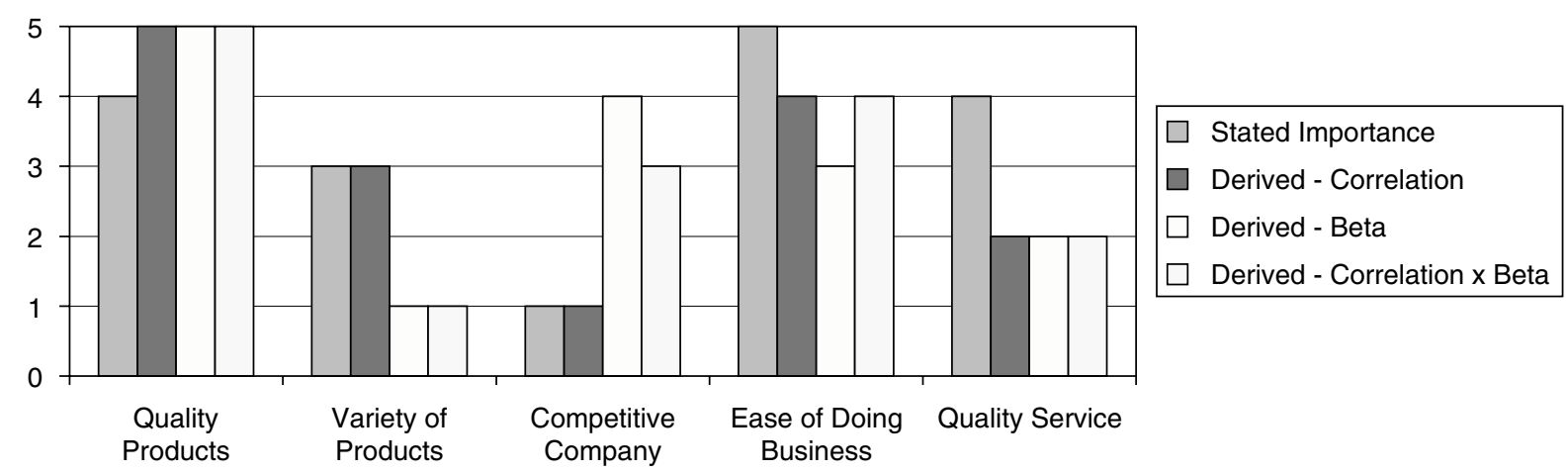

Figure 2: Year Two stated and derived importance scores ranked to demonstrate divergence

were not significantly correlated. With the exception of the factor that was deemed most important and the one that was deemed the fourth most important (out of five factors), the rank order of factors was different. Consequently, management would have different targets for improvement depending on which technique was used to calculate importance.

When using the product of beta weights and correlation coefficients (combined score) to derive importance values, findings are nearly identical to those obtained when using regression analysis. The ranking of the five factors based on the combined scores was nearly perfectly correlated with the ranking when using the beta weights. Therefore, the same problems could exist when taking action on this data as described in the discussion of results for using regression analysis.

Additionally, the derived importance obtained when using regression analysis resulted in one factor (variety of products) having a negative or, what some researchers might call, a nonsignificant importance score. Without careful analysis and perhaps further insight into the minds of these customers, management might interpret this to mean that their vast array of products is a dissatisfier and seek to eliminate some products from their line. This is a good example of an attribute that is a basic or minimum requirement but one that does not significantly impact customer satisfaction unless it is absent from the mix of products and services offered.

\section{DISCUSSION AND IMPLICATIONS}

First, the present study provides evidence that rating-scale measures of stated importance may not be as autonomously useful for guiding managerial decisions as derived measures of importance. For both years for which data sets are analysed, measures that ask respondents to rate the importance of attributes on a (7-point) scale yield high ratings for all attributes with very little variability among them, thus making it difficult for the decision maker to determine how to proceed to increase satisfaction. If respondents do not discriminate among attributes, the research is of little value in guiding managerial action, as every attribute appears to be of equal and urgent importance.

It is possible that other measures of stated importance, such as rankings or constant sum measures, may yield different and more useful results, and should be examined in future research. Indeed, the greater respondent burden associated with these more cognitively complex methodologies may be overcome by the beneficial value of the information rendered.

Secondly, the findings of the present study suggest that measures of derived importance are more sensitive than scale-based measures of stated importance. Even when scale-based measures of stated importance do not change significantly, corresponding derived importance measures, both correlation-based and regression-based, may yield differing results. In Years One and Two, for example, the scale-based measures of stated 
importance differ very little from each other in the range of scores and in the rank ordering of attributes. For the same years, the correlation-based measures vary significantly, with Year One results showing no relationships with satisfaction and Year Two showing several stronger relationships between attributes and satisfaction. The regression-based measures also differ from Year One to Year Two, in rank ordering of attributes and in strength of association.

Finally, the present study's findings highlight the significance of the researcher's expertise in assigning meaning to apparently incongruous statistical results. For both years in which data are analysed, two measures of derived importance result in equivalent rank orderings of attributes, with the third measure in apparent disagreement.
One potential mechanism for reconciling the divergence of results and guiding action is to resist selecting one methodology over the other and instead integrate both stated and derived measures based on rankings. Kano et al. ${ }^{55}$ have provided a framework for accomplishing this, and Figure 3 demonstrates how his approach can be adapted to this analysis.

Attributes identified as important under both the stated and the derived techniques (eg quality of products) are certainly worthy of organisational intervention, as their presence can promote satisfaction while their absence may induce dissatisfaction. ${ }^{56}$ Those identified as lesser in importance on both techniques (eg competitive company) should not be considered priority action items, as these may be attributes that are unexpected, undesired, unnecessary or noncontributory to overall customer satisfaction.

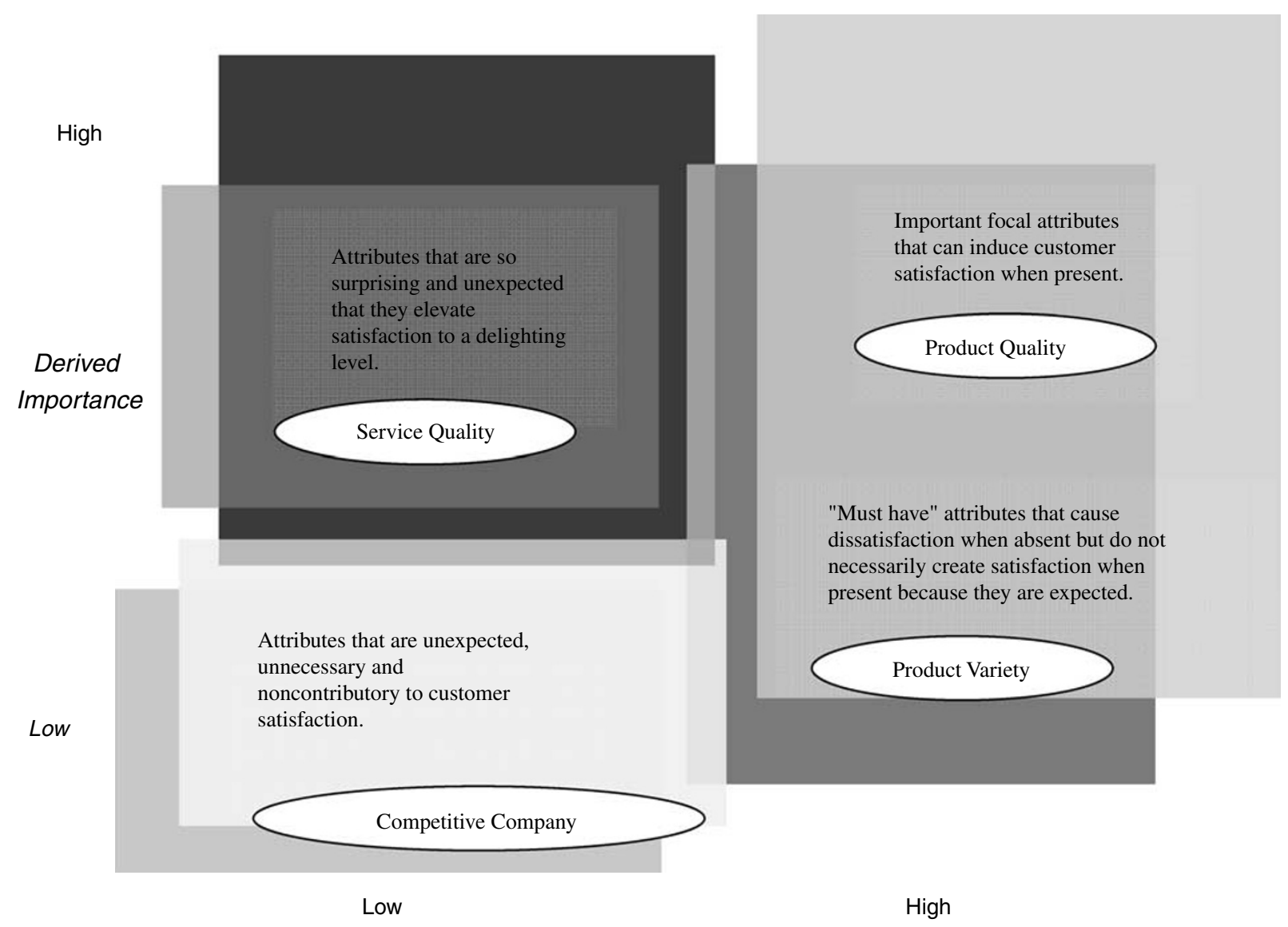

Stated Importance

Figure 3: A model for integrating derived and stated importance results 
Attributes identified in stated measures as important, but not computed to be so using derived techniques (eg variety of products) are considered potential dissatisfiers, in that their expected presence will not make consumer happy but their absence may surely send your customers to competing firms. These attributes represent minimum expectations for transacting business with the firm. Finally, those attributes high in derived importance but lower ranked in stated importance (eg quality service) are potential 'delighters'. These are the attributes that customers do not necessarily expect, but their presence can lead to surprising elation. In short, these are potential firm differentiators that should be nonimitatable and unique to the firm.

This analysis of the various techniques associated with examining importance as it relates to customer satisfaction measurement further suggests that the science of measurement is enhanced by the art of understanding the world as it is. Explicit knowledge gained from the scientific method is very important but it may be insufficient for making wise judgments. Implicit knowledge that decision makers gather from experience may be just as important. This tacit and informal knowledge may be hard to express and difficult to share, but when combined with explicit knowledge, may result in the highest quality decisions. When real-world research is not clean and orderly, subjectivity (based on experience and reflection) may lead to wise decisions. ${ }^{57}$

Adding subjectivity to a combination of techniques may provide more accurate and actionable improvements than simply relying on one method of analysis. Ideally, the decision maker should be as rational, analytical, deliberate and scientific as possible. ${ }^{58}$ Subjectivity also, however, has a place in decision making, particularly for those with substantial experience. Intuitive decision making involves both judgment as well as 'gut feelings' and is an unconscious expertise that allows a person to make sense of uncertain data. ${ }^{59}$ Just as we need to balance the scientific method and subjectivity, we need to balance rationality and intuition when deciding upon actionable items.

\section{References}

1 Hauser, J. R. (1991) 'Comparison of importance measurement methodologies and their relationship to customer satisfaction', M.I.T. Marketing Center Working Paper 91, January.

2 Green, P. E. and Tull, D. S. (1975) 'Research for Marketing Decisions', 3rd edn, Prentice-Hall, Inc., Englewood Cliffs, NJ, pp. 478-484.

3 Customer Satisfaction Research Institute (1991) 'Measuring importance', White Paper.

4 Di Paula, A. (June 7, 1999) 'Assessing customer values: Stated importance versus derived importance', Marketing News, Vol. 33, No. 12, p. H39.

5 Chu, R. (2002) 'Stated-importance versus derived-importance customer satisfaction measurement', The Journal of Services Marketing, Vol. 16, No. 4, p. 285.

6 Hanson, R. (1992) 'Determining attribute importance', Quirk's Marketing Research Review, October, available at http://www. quirks.com/articles/article.asp?arg_articleid $=430$.

7 Venkitaraman, R. K. and Jaworski, C. M. (1993) 'Restructuring customer satisfaction measurement for better resource allocation decisions: An integrated approach', presented at the Fourth Annual Advanced Research Techniques Forum of the American Marketing Association, 15 June.

8 Reichfiels, F. F. (Dec 2003) 'The one number you need to grow', Harvard Business Review, Vol. 81, No. 12, pp. 46-54.

9 Kristensen, K. and Westland, A. (April 2004) 'Letter to the editor: The number you need to grow', Harvard Business Review, Vol. 82, No. 4, pp. 136-137.

10 Morgan, N. A. and Rego, L. L. (April 2004) 'Letter to the editor: The number you need to grow', Harvard Business Review, Vol. 82, No. 4, pp. 134-136.

11 Chiquan, G. and Jiraporn, P. (June 2005) 'Customer satisfaction, net income and total assets: An exploratory study', Journal of Targeting, Measurement \& Analysis for Marketing, Vol. 13, No. 4, pp. 346-353.

12 Neil, T., Martz, B. and Biscaccanti, A. (2004) 'Eliciting implicit paradigms in allocating resources 'Satisficing' performance and 'Illusion of Control”, Management Decision, Vol. 47, No. 4, pp. $566-582$.

13 Hanson (October, 1992) op. cit.

14 Chu (2002) op. cit.

15 Bhote, K. R. (1998) 'The Customer Loyalty Audit', Cambridge Strategy Publications, Alexandria, VA.

16 Hanson (October, 1992) op. cit.

17 Hauser, J. R. (1991) 'Comparison of importance measurement methodologies and their relationship to customer satisfaction', M.I.T. Marketing Center Working Paper 91, Cambridge, MA, January.

18 Hanson (October 1992) op. cit.

19 Grisaffe, D. (1993) 'Appropriate use of regression in customer satisfaction analyses: A response to William McLauchlan', Quirk's Marketing Research Review, February, available at http://www.quirks.com/articles/article.asp?arg_articleid=189.

20 Customer Satisfaction Research Institute (1991) op. cit.

21 Grisaffe (February 1993) op. cit.

22 Di Paula (7 June 1999) op. cit.

23 Di Paula (7 June 1999) Ibid.

24 Grisaffe (February 1993) op. cit.

25 Grisaffe (February 1993) Ibid.

26 Hofstede, F. T., Kim, Y. and Wedel, M. (22 May 2002) 'Bayesian prediction in hybrid conjoint analysis', Journal of Marketing Research, Vol. 39, No. 2, p. 253. 
27 Hanson (October 1992) op. cit.

28 Grisaffe (February 1993) op. cit.

29 McLauchlan, W. (1993) 'A Response to Grisaffe',Quirk's Marketing Research Review, February, available at http://www.quirks.com/articles/article.asp?arg_articleid=188.

30 Chu (2002) op. cit.

31 Hanson (October 1992) op. cit.

32 Grisaffe (February 1993) op. cit.

33 Chu (2002) op. cit.

34 McLauchlan, W. (October 1992) 'Regression-based satisfaction analyses: Proceed with caution', Quirk's Marketing Research Review, pp. 10-13.

35 Chu (2002) op. cit.

36 Hanson (October 1992) op. cit.

37 Green, P. E. and Tull, D. S. (1975) op. cit.

38 McLauchlan (October 1992) op. cit.

39 Grisaffe (February 1993) op. cit.

40 McLauchlan (February 1993) op. cit.

41 Chu (2002) op. cit.

42 McLauchlan (February 1993) op. cit.

43 Grisaffe (February 1993) op. cit.

44 Di Paula (7 June 1999) op. cit.

45 Chu (2002) op. cit.

46 Grisaffe (February 1993) op. cit.

47 Di Paula (7 June 1999) op. cit.

48 Chu (2002) op. cit.
49 Hanson (October 1992) op. cit.

50 Hanson (October 1992) op. cit.

51 Di Paula (7 June 1999) op. cit.

52 Gustafsson, A. and Johnson, M. D. (November 2004) 'Determining attribute importance in a service satisfaction model', Journal of Service Research, Vol. 7, No. 2, p. 124.

53 Customer Satisfaction Research Institute (1991) op. cit.

54 Hair, J. F., Anderson, R. and Black, W. C. (1995) 'Multivariate Data Analysis with Readings', Prentice-Hall, Inc., Englewood Cliffs, NJ

55 Kano, N., Seraku, N., Takahashi, F. and Tsuji, S. (1984) 'Attractive quality and must-be quality', Quality: The Journal of the Japanese Society for Quality Control, Vol. 14(April), pp. 39-48.

56 Rust, R. T. and Oliver, R. L. (2000) 'Should we delight the customer?' Journal of the Academy of Marketing Science, Vol. 28, No. 1, pp. 86-94.

57 Sternberg, R. J. (2001) 'Why schools should teach wisdom: The balance theory of wisdom in educational settings', Educational Psychologist, Vol. 36, No. 4, pp. 227-245.

58 Miller, C. C. and Ireland, R. D. (February 2005) 'Intuition in strategic decision making: Friend or foe in the fast-paced 21st century?' Academy of Management Executive, Vol. 19, No. 1, p. 19.

59 Sadler-Smith, E. and Shefy, E. (November 2004) 'The intuitive executive: Understanding and applying 'Gut Feel' in decisionmaking’, Academy of Management Executive, Vol. 18, No. 4, pp. 76-91. 